Journal of Mechanical Engineering and Sciences

ISSN (Print): 2289-4659; e-ISSN: 2231-8380

Volume 12, Issue 4, pp. 4161-4179, December 2018

(C) Universiti Malaysia Pahang, Malaysia

DOI: https://doi.org/10.15282/jmes.12.4.2018.13.0359

\title{
Real-time implementation of an enhanced nonlinear PID controller based on harmony search for one-stage servomechanism system
}

\author{
Mohamed. A. Shamseldin ${ }^{*}$, Mohamed Sallam ${ }^{2}$, A. M. Bassiuny ${ }^{3}$ \\ and A. M. Abdel Ghany ${ }^{4}$ \\ ${ }^{1}$ Mechanical Engineering Department, Future University in Egypt, Egypt \\ *Email: Mohamed.abelbbar@fue.edu.eg \\ ${ }^{2,3}$ Mechanical Engineering Department, Helwan University, Egypt \\ ${ }^{4}$ Electrical Power Dept., October 6 University (Helwan University Originally), Egypt
}

\begin{abstract}
This paper presents a real-time implementation of an enhanced nonlinear PID (NPID) controller to follow a preselected position profile of one stage servomechanism drive system. This purpose should be realized regardless the different operating points and external disorders (friction and backlash). In this study, the MATLAB Simulink used for purpose of controller design while the result from simulation will be executed in real time using LABVIEW software. There is not enough information about the servomechanism experimental setup so, the system identification techniques will be used via collecting experimental input/output data. The optimum parameters for the controllers have been obtained via harmony search optimization technique according to an effective cost function. Also, the performance of enhanced NPID controller has been investigated by comparing it with linear PID controller. The experimental and simulation results show that the proposed NPID controller has minimum rise time and settling time through constant position reference test. Also, the NPID control is faster than the linear PID control by $40 \%$ in case of variable position reference test.
\end{abstract}

Keywords: Nonlinear PID (NPID); Harmony Search (HS); Servomechanism.

\section{INTRODUCTION}

The latest development of machine tools is to achieve high-speed spindle and feed drives, which lead to improve the performance and reduce the machining cycle times [1]. Also, the design of feed drives with an adequate dynamic response and good performance became essential in the industrial field. The purpose of servo control systems to maintain the stage follow a preselected position profile along complicated trajectories at high feed speeds [2].

Traditional machine tool feed drives use the proportional position control, which leads to high fluctuation in stage and large tracking errors at high speeds [3]. The tracking error is eliminated using high-performance feed drive motors with advanced control techniques. However, friction on the lead screw and the guides, cutting force disturbance, and changes in the workpiece mass in linear drives are obstacles to achieve good contouring accuracy at high feeds [4].

The requirements for high-speed accurate contouring have led to the investigation of efficient control algorithms in recent years [5]. Proportional-Integral-Derivative (PID) 
controllers have been used for systems control in many industrial applications. The PID controller algorithm is simple and has acceptable performance for many of the common systems which make it used for several decades [6]. The behavior of the PID controller is highly affected by selecting its parameters. Until now, there is not a definite ideal method to select the proper PID controller parameters for a certain system [7]. In the last period, the researchers resort to use the optimization techniques such as Genetic Algorithm (GA), Particle Swarm Optimization (PSO), Ant Colony Optimization and Harmony Search (HS) optimization to find the optimum parameters of PID controller away from the rough methods (Ziegler-Nichols method) which cannot guarantee the proper selection for those parameters [8]. The optimization techniques cannot carry out it practically in real time where it takes a long time to find the optimum solution. So, we resort to the offline tuning using an accurate mathematical model for the system but, the lack of system parameters data is an obstacle to achieve this purpose [9].

The most of real systems are nonlinear systems but, the nonlinearity percentage tolerances from system to another [10]. It is known that the mechanical systems, for example, the one stage servomechanism system contains a high percentage of nonlinearity where the friction of guides and the backlash between the nut and the screw [11]. So, the traditional PID controller with linear parameters cannot achieve high performance for this type of systems. Also, The PID controller still has fixed gains which are not enough to deal with high complicated dynamic systems [12].

The recent research proceeded to design nonlinear PID control to overcome the nonlinearity and uncertainty of system. The nonlinear PID (NPID) controller contains nonlinear gains incorporated with the fixed gains of PID controller [13]. These nonlinear gains enjoy the advantage of high initial gain to attain a fast dynamic response, followed by a low gain to prevent an oscillatory behavior [14].

Most of current studies don't present obvious method to obtain the NPID control parameters [15]. Also, the previous research is limited to simulations without practical implementation. This study presents a practical methodology to design a new form of nonlinear PID control. It is known that MATLAB Simulink is a powerful tool to simulate and design most of the control systems but it is not suitable and reliable with the real-time implementation of control systems [16]. So, this study uses MATLAB Simulink only for purposes of control design and the obtained results from simulation will be executed practically by LABVIEW software using NI 6009 DAQ card. Several parameters of the experimental setup aren't known so, this research resorted to using the system identification techniques (linear and nonlinear least squares methods) to develop an identified model which will be used in control design. The optimum parameters of the proposed controller had been obtained offline using harmony search optimization technique based on a certain cost function.

The paper is organized as follows: Section II illustrates the system modeling and identification. The enhanced nonlinear PID controller is involved in Section III. Section IV shows the experimental results. Lately, Section V presents the conclusion.

\section{SYSTEM MODELING AND IDENTIFICATION}

\section{System Modeling}

The structure of the lead-screw-driven stage is shown in figure 1. The stage is supported by linear guides on a bed. The driving mechanism consists of a DC motor, a coupling, a screw shaft, and a nut. The DC motor rotates the screw shaft while the nut converts rotary 
motion to translational motion and drives the stage. The speed and position of the stage are measured by a rotary encoder coupled with screw shaft [3].

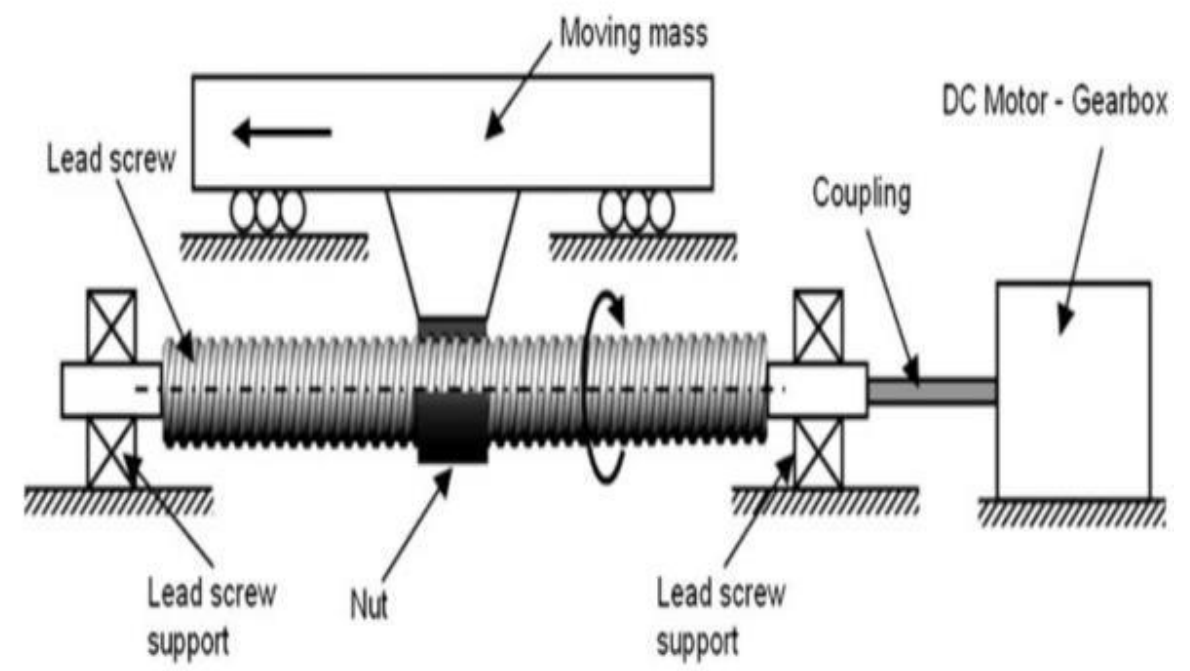

Figure 1. The structure of lead screw drive system.

A four-inertia model of a lead screw driving system as shown in figure 2 . This model deals with each component as a lumped constant, and the four moments of inertia of the components are connected by stiffness and damping parameters. The four inertia parameters are the moment of inertia of the rotor $\left(J_{m}\right)$, the moment of inertia of the screw shaft $\left(J_{b}\right)$, the mass of the screw shaft $\left(M_{b}\right)$, and the mass of the stage $\left(M_{t}\right)$. Each inertia parameter in the four-inertia model is defined in table 1 . The moment of inertia of the rotor and that of the screw shaft (which are connected by the torsional stiffness of the coupling) is rotated by the motor torque, where $\theta_{m}$ and $\theta_{b}$ represent motor angle and screw-shaft angle. The motion of the screw shaft in the $\mathrm{x}$-direction is considered, and the mass of the screw shaft is supported by the axial stiffness of the screw shaft and its bearing, where $X_{b}$ represents the gap between the screw shaft and nut (backlash) [3].

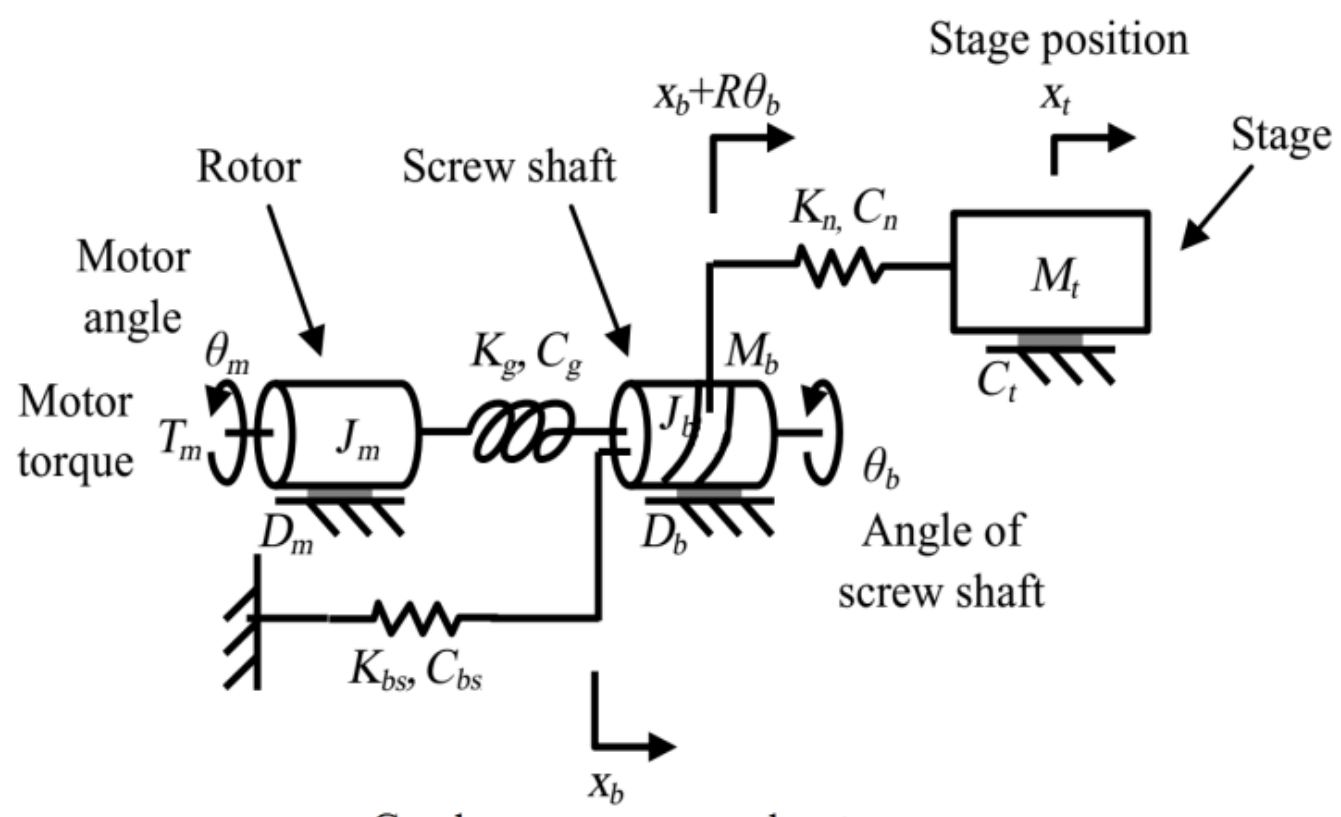

Gap between screw and nut

Figure 2. Four-inertia model of lead screw driven stage. 
The rotary motion of the screw shaft is converted to a translational motion by the nut, and $X_{b}+R \theta_{b}$ represents the position at which the nut is mounted. The $R$ is a conversion factor of the lead screw. The mass of the stage and the nut mounting position are connected through the axial stiffness of the nut, and $X_{t}$ represents the stage position. The complete system parameters are demonstrated in table 1 . The model differential equations can be described as follows:

$$
\begin{gathered}
J_{m} \cdot \ddot{\theta}_{m}+D_{m} \cdot \dot{\theta}_{m}+C_{g} \cdot\left(\dot{\theta}_{m}-\dot{\theta}_{b}\right)+K_{g} \cdot\left(\theta_{m}-\theta_{b}\right)=T_{m} \\
J_{b} \cdot \ddot{\theta}_{b}+D_{b} \cdot \dot{\theta}_{b}+R \cdot\left[C_{n}\left(R \cdot \dot{\theta}_{b}+\dot{X}_{b}-\dot{X}_{t}\right)+K_{n} \cdot\left(R \cdot \theta_{b}+X_{b}-X_{t}\right)\right]=C_{g} \cdot\left(\dot{\theta}_{m}-\dot{\theta}_{b}\right)+ \\
K_{g} \cdot\left(\theta_{m}-\theta_{b}\right) \\
M_{b} \cdot \ddot{X}_{b}+C_{b s} \cdot \dot{X}_{b}+K_{b s} \cdot X_{b}+C_{n} \cdot\left(R \cdot \dot{\theta}_{b}+\dot{X}_{b}-\dot{X}_{t}\right)+K_{n} \cdot\left(R \cdot \theta_{b}+X_{b}-X_{t}\right)=0 \\
M_{t} \cdot \ddot{X}_{t}+C_{t} \cdot \dot{X}_{t}=C_{n} \cdot\left(R \cdot \dot{\theta}_{b}+\dot{X}_{b}-\dot{X}_{t}\right)+K_{n} \cdot\left(R \cdot \theta_{b}+X_{b}-X_{t}\right)
\end{gathered}
$$

Table 1. Model Parameters.

\begin{tabular}{ccll}
\hline No. & Parameter & \multicolumn{1}{c}{ Unit } & \multicolumn{1}{c}{ Content } \\
\hline $\mathbf{1}$ & $J_{m}$ & $\mathrm{~kg} \cdot \mathrm{m} 2$ & Moment inertia of DC motor rotor \\
$\mathbf{2}$ & $J_{b}$ & $\mathrm{~kg} \cdot \mathrm{m} 2$ & Moment inertia of screw shaft \\
$\mathbf{3}$ & $M_{b}$ & $\mathrm{~kg}$ & Mass of screw shaft \\
$\mathbf{4}$ & $M_{t}$ & $\mathrm{~kg}$ & Mass of Stage \\
$\mathbf{5}$ & $K_{g}$ & $\mathrm{~N} \cdot \mathrm{m} / \mathrm{rad}$ & Torsional stiffness of screw shaft and coupling \\
$\mathbf{6}$ & $K_{b s}$ & $\mathrm{~N} / \mathrm{m}$ & Axial stiffness of screw shaft and bearing \\
$\mathbf{7}$ & $K_{n}$ & $\mathrm{~N} / \mathrm{m}$ & Axial stiffness of nut \\
$\mathbf{8}$ & $D_{m}$ & $\mathrm{~N} \cdot \mathrm{m} /(\mathrm{rad} / \mathrm{s})$ & Rotational viscous damping of the motor \\
$\mathbf{9}$ & $D_{b}$ & $\mathrm{~N} \cdot \mathrm{m} /(\mathrm{rad} / \mathrm{s})$ & Rotational viscous damping of screw shaft and bearing \\
$\mathbf{1 0}$ & $C_{t}$ & $\mathrm{~N} /(\mathrm{m} / \mathrm{s})$ & Axial viscous damping of stage \\
$\mathbf{1 1}$ & $R$ & $\mathrm{~m} / \mathrm{rad}$ & Conversion factor of lead screw \\
$\mathbf{1 2}$ & $C_{g}$ & $\mathrm{~N} \cdot \mathrm{m} /(\mathrm{rad} / \mathrm{s})$ & Rotational viscous damping of screw shaft and coupling \\
$\mathbf{1 3}$ & $C_{b s}$ & $\mathrm{~N} /(\mathrm{m} / \mathrm{s})$ & Axial viscous damping of screw shaft and bearing \\
$\mathbf{1 4}$ & $C_{n}$ & $\mathrm{~N} /(\mathrm{m} / \mathrm{s})$ & Axial viscous damping of nut \\
$\mathbf{1 5}$ & $\theta_{m}$ & $\mathrm{rad}$ & Motor shaft angle \\
$\mathbf{1 6}$ & $\theta_{b}$ & $\mathrm{rad}$ & Screw shaft angle \\
$\mathbf{1 7}$ & $X_{b}$ & $\mathrm{~m}$ & Gap between screw shaft and nut (backlash) \\
$\mathbf{1 8}$ & $X_{t}$ & $\mathrm{~m}$ & Stage position \\
$\mathbf{1 9}$ & $T_{m}$ & $\mathrm{~N} \cdot \mathrm{m}$ & The DC motor torque \\
\hline
\end{tabular}

\section{System Identification}

It is known that several of servomechanism system parameters cannot be estimated easily. Therefore, most of the researchers neglect it which will be lead to errors in the design of their own controllers [17]. So, this research resorts to system identification is to determine the parameters of the model system using experimental input and output data. The method to develop a model involves three basic steps. The first step is the input and output data [18]. These data are collected from the experiment. The next step is the set of candidate models. We have to investigate an appropriate model from the set of candidate models. It is known that the nonlinear system cannot be represented exactly by linear models [3]. The accuracy of the model can be increased by increasing the order of the linear system. However, often there is a limitation that increasing order cannot improve the model 
accuracy sufficiently. Therefore, it is necessary to explicitly add the nonlinearities into the system [19].

In this paper, we try using the nonlinear ARX model structure to model such systems where AR refers to autoregressive part and X to the extra input. A nonlinear ARX model can be understood as an extension of a linear model as shown in figure 3 .

\section{Nonlinearity Estimator}

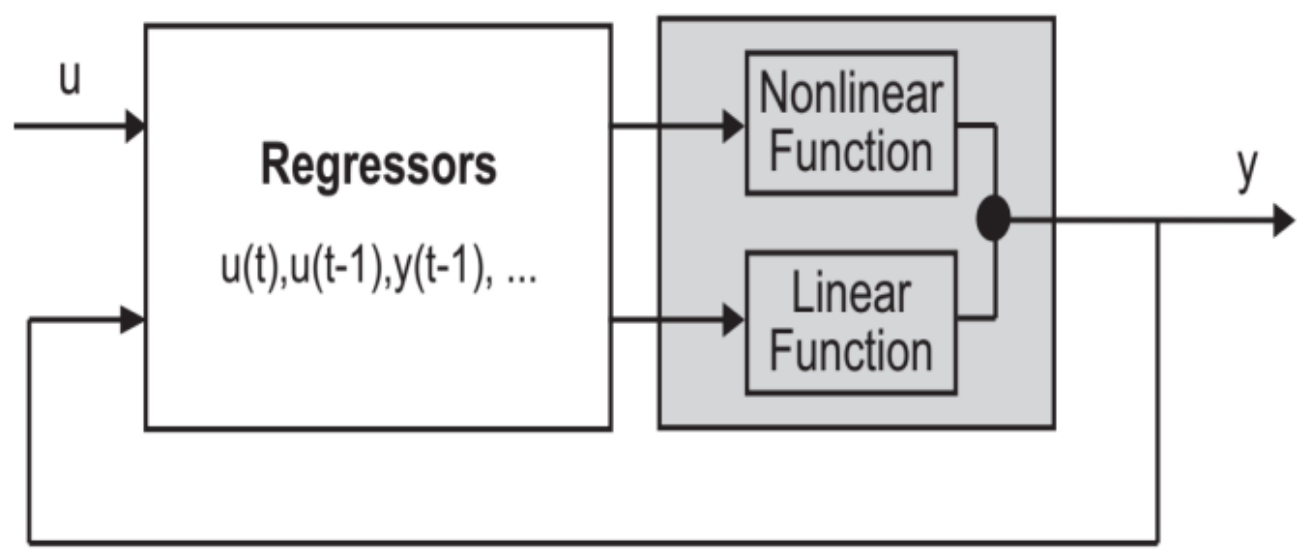

Figure 3. The structure of a nonlinear ARX model.

These models are defined as those that have a nonlinear dependence on their parameters. For example, Eq. (5).

$$
f(x)=a_{0}\left(1-e^{-a_{1} x}\right)+e
$$

To illustrate how this is done, first the relationship between the nonlinear equation and the data can be expressed generally as

$$
y_{i}=f\left(x_{i} ; a_{0}, a_{1}, \ldots \ldots, a_{m}\right)+e_{i}
$$

Where $y_{i}$ is a measured value of the dependent variable, $f\left(x_{i} ; a_{0}, a_{1}, \ldots \ldots, a_{m}\right)$ is a function of the independent variable $x_{i}$ and a nonlinear function of the parameters $a_{0}, a_{1}, \ldots \ldots, a_{m}$, and $e_{i}$ is a random error.

This model can be expressed in abbreviated form by omitting the parameters,

$$
y_{i}=f\left(x_{i}\right)+e_{i}
$$

The nonlinear model can be expanded in a Taylor series around the parameter values,

$$
f\left(x_{i}\right)_{j+1}=f\left(x_{i}\right)_{j}+\frac{\partial f\left(x_{i}\right)_{j}}{\partial a_{0}} \Delta a_{0}+\frac{\partial f\left(x_{i}\right)_{j}}{\partial a_{1}} \Delta a_{1}
$$

where $\mathrm{j}=$ the initial guess, $\mathrm{j}+1=$ the prediction, $\Delta a_{0}=a_{0, j+1}-a_{0, j}$ and $\Delta a_{1}=a_{1, j+1}-$ $a_{1, j}$

by substitute Eq. (8) in Eq. (7) will result Eq. (9).

$$
y_{i}-f\left(x_{i}\right)_{j}=\frac{\partial f\left(x_{i}\right)_{j}}{\partial a_{0}} \Delta a_{0}+\frac{\partial f\left(x_{i}\right)_{j}}{\partial a_{1}} \Delta a_{1}+e_{i}
$$


or in matrix form

$$
\{D\}=\left[Z_{j}\right]\{\Delta A\}+\{E\}
$$

where $\left[Z_{j}\right]$ is the matrix of partial derivatives of the function evaluated at the initial guess $\mathrm{j}$,

$$
\left[Z_{j}\right]=\left[\begin{array}{cc}
\partial f_{1} / \partial a_{0} & \partial f_{1} / \partial a_{1} \\
\partial f_{2} / \partial a_{0} & \partial f_{2} / \partial a_{1} \\
\ldots \ldots & \ldots \ldots \ldots \\
\partial f_{n} / \partial a_{0} & \partial f_{n} / \partial a_{1}
\end{array}\right]
$$

where $\mathrm{n}=$ the number of data points

The vector $\{D\}$ contains the differences between the measurements and the function values,

$$
\{D\}=\left\{\begin{array}{c}
y_{i}-f\left(x_{1}\right) \\
y_{2}-f\left(x_{2}\right) \\
\ldots \ldots \ldots \\
y_{n}-f\left(x_{n}\right)
\end{array}\right\}
$$

The vector $\{\Delta A\}$ contains the changes in the parameter values,

$$
\{\Delta A\}=\left\{\begin{array}{c}
\Delta a_{0} \\
\Delta a_{1} \\
\cdots \cdots \\
\Delta a_{m}
\end{array}\right\}
$$

Applying linear least-squares theory to Eq. (10)

$$
\begin{aligned}
& \left\{\left[Z_{j}\right]^{T}\{D\}\right\}=\left[Z_{j}\right]^{T}\left[Z_{j}\right]\{\Delta A\} \\
& \{\Delta A\}=\left[\left[Z_{j}\right]^{T}\left[Z_{j}\right]\right]^{-1}\left\{\left[Z_{j}\right]^{T}\{D\}\right\}
\end{aligned}
$$

for $\{\Delta \mathrm{A}\}$, which can be employed to compute improved values for the parameters, as in

$$
\begin{gathered}
a_{0, j+1}=a_{0, j}+\Delta a_{0} \\
a_{1, j+1}=a_{1, j}+\Delta a_{1}
\end{gathered}
$$

\section{Experimental Setup}

Figure 4 illustrates the main components of one stage table servomechanism experimental setup which consists of seven parts as the following.

1) One Stage Table: The DC Motor Electro-Mechanical Module demonstrates closedand open-loop positioning control concepts as well as some electromechanical principles. The stroke of table ranges from 0 to 9 Inch. It consists of a DC motor driving a lead screw on which a sliding block is installed. The DC motor has nominal speed $1800 \mathrm{rev} / \mathrm{min}$, and armature voltage $90 \mathrm{~V}$ dc motor.

2) Optical Encoder: An encoder is an electrical mechanical device that can monitor motion or position. A typical encoder uses optical sensors to provide a series of pulses that can be translated into motion. The Optical Encoder is an add-on that provides position feedback signals (100 pulses per revolution).

3) Limit Switches: Two magnetic limit switches detect when the sliding block reaches the start or end position. 
4) Motor Driver: The DC Motor Drive controls the DC Motor Electro-Mechanical Module, Model 3293. The drive is configured to operate the motor at one of two user defined speeds. Input signals are used to switch between the two set speeds, to select the direction of motion (forward or reverse), and to enable the movement. Also, this versatile drive allows us to enter an external signal ( -5 to $5 \mathrm{~V})$ to control in the motor speed.

5) A data acquisition card (DAQ) NI USB-6009: it has the following specifications:

6) 8 analog inputs (12-bit, $10 \mathrm{kS} / \mathrm{s})$.

7) 2 analog outputs (12-bit, $150 \mathrm{~S} / \mathrm{s})$.

8) 12 digital I/O.

9) USB connection, no extra power supply needed.

10) Push Buttons, Toggle Switches, and Lights: they use to operate the DC motor driver manually.

11) Computer used to perform the control algorithms and receive and send the signals from the NI DAQ Card.

LabVIEW programs or virtual instruments (VIs) have two main parts: The first is the front panel. The front panel is the interactive user interface of a VI [20]. It can contain knobs, push buttons, graphs and many other controls and indicators [21]. The second is the block diagram. The block diagram is the VI's source code which is constructed in the LabVIEW's graphical program language [22].

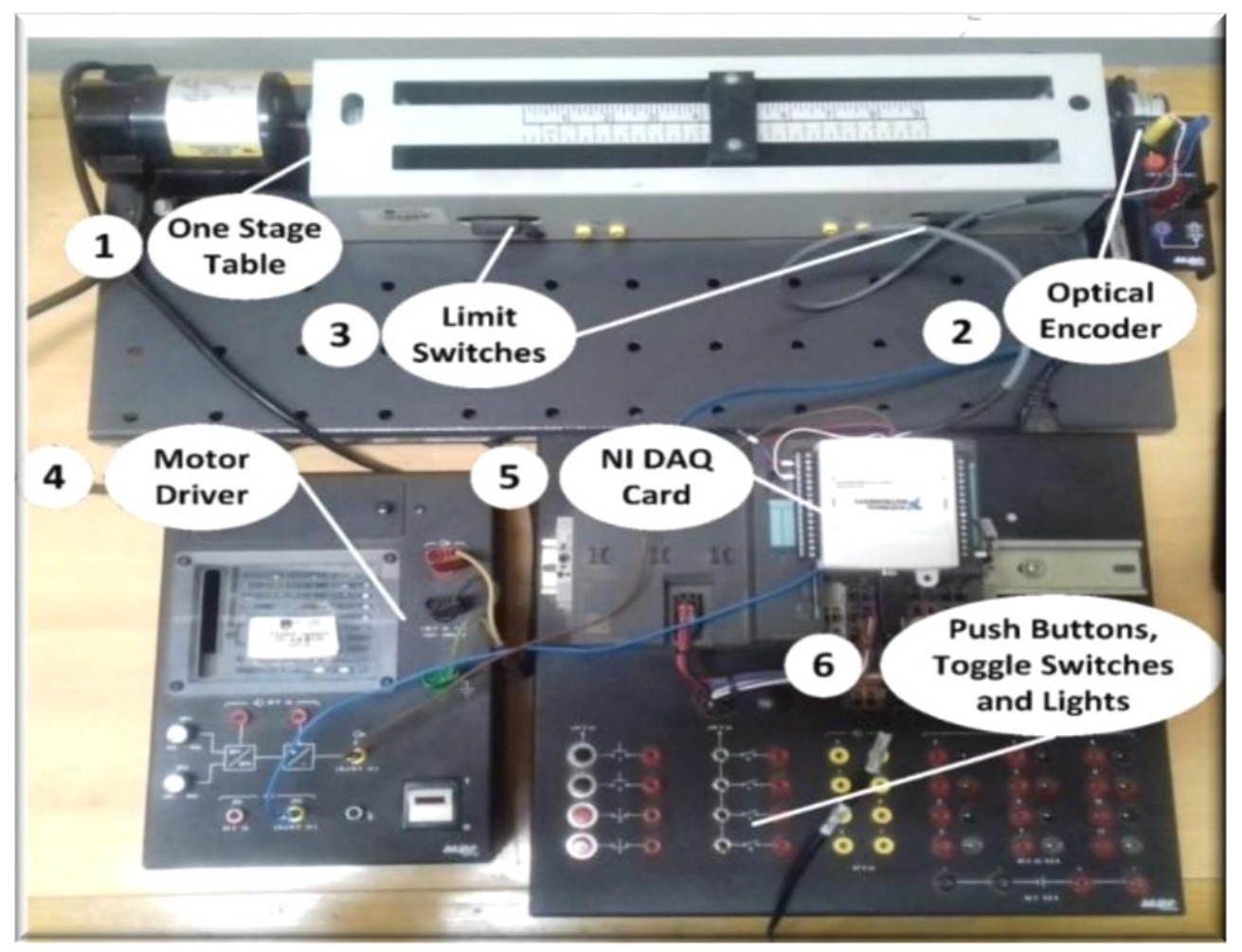

Figure 4. One Stage Table Servomechanism Experimental Setup.

The main idea of the program design is to create the VI that can generate the analog output signal to control the instrument or experiment and collect the analog input signal from the 
experiment at the same time. The details of requirements in the signal generation part and the data acquisition part are described in the following paragraph [20], [21].

The designed program will make the NI DAQ Card generate random signal ranges from $-5 \mathrm{~V}$ to $+5 \mathrm{~V}$ with sample rate 50 milliseconds. This signal will be input to the DC motor drive as shown in figure 5. The speed of DC motor will fluctuate with change the generated signal. The positive voltage range of output signal will be made the DC motor speed fluctuate in the forward direction while the DC motor speed has fluctuated in reverse direction through the negative voltage range. The shaft of the optical encoder will be coupled with lead screw shaft to measure the speed and position of the table.

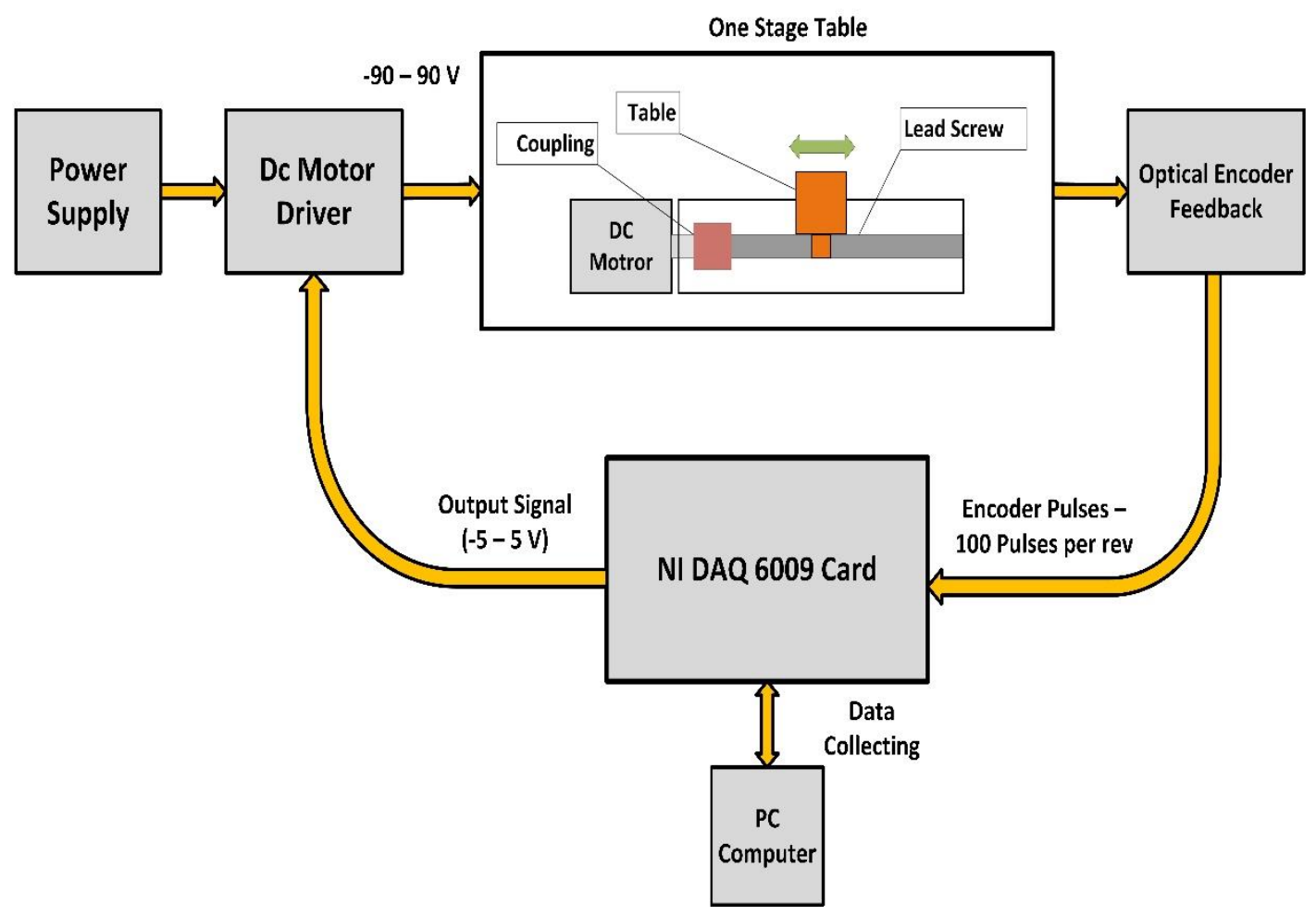

Figure 5. Block diagram of experimental setup servomechanism system.

The front panel enables the user to change the input signal to the DC motor driver randomly as shown in figure 6 . This continuous change in input signal will make the speed of one stage table fluctuate proportionally as illustrated in figure 7 . Figure 8 shows the actual position of one stage table through the experiment. It can be noted that the table position increases in positive ranges of the input signal to DC motor driver while the position decreases in negative ranges of the input signal. The data will be collected and stored in excel sheet file and then this data will be used to can fabricate identified model for one stage servomechanism system. 


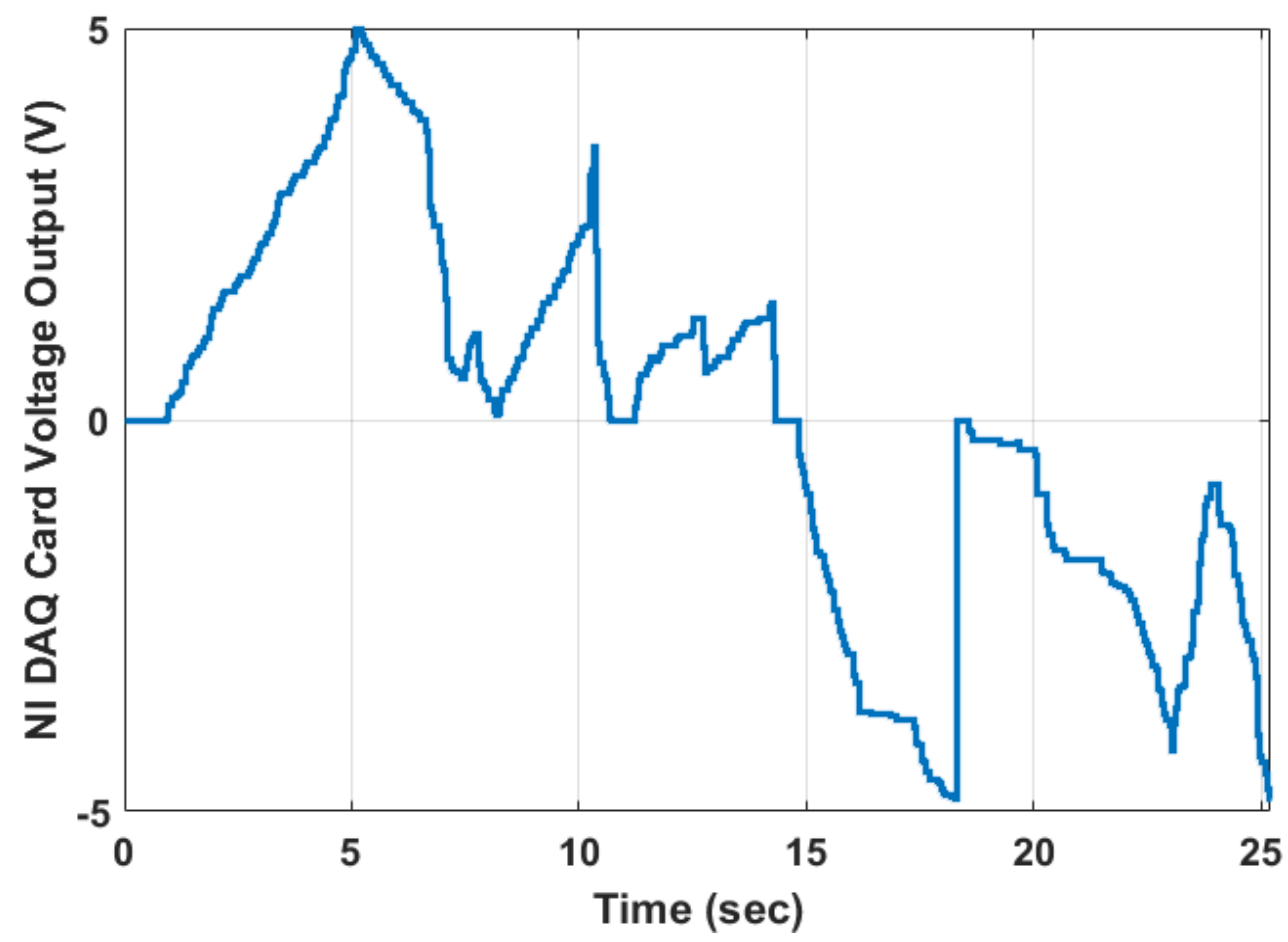

Figure 6. Random input signal to DC motor driver.

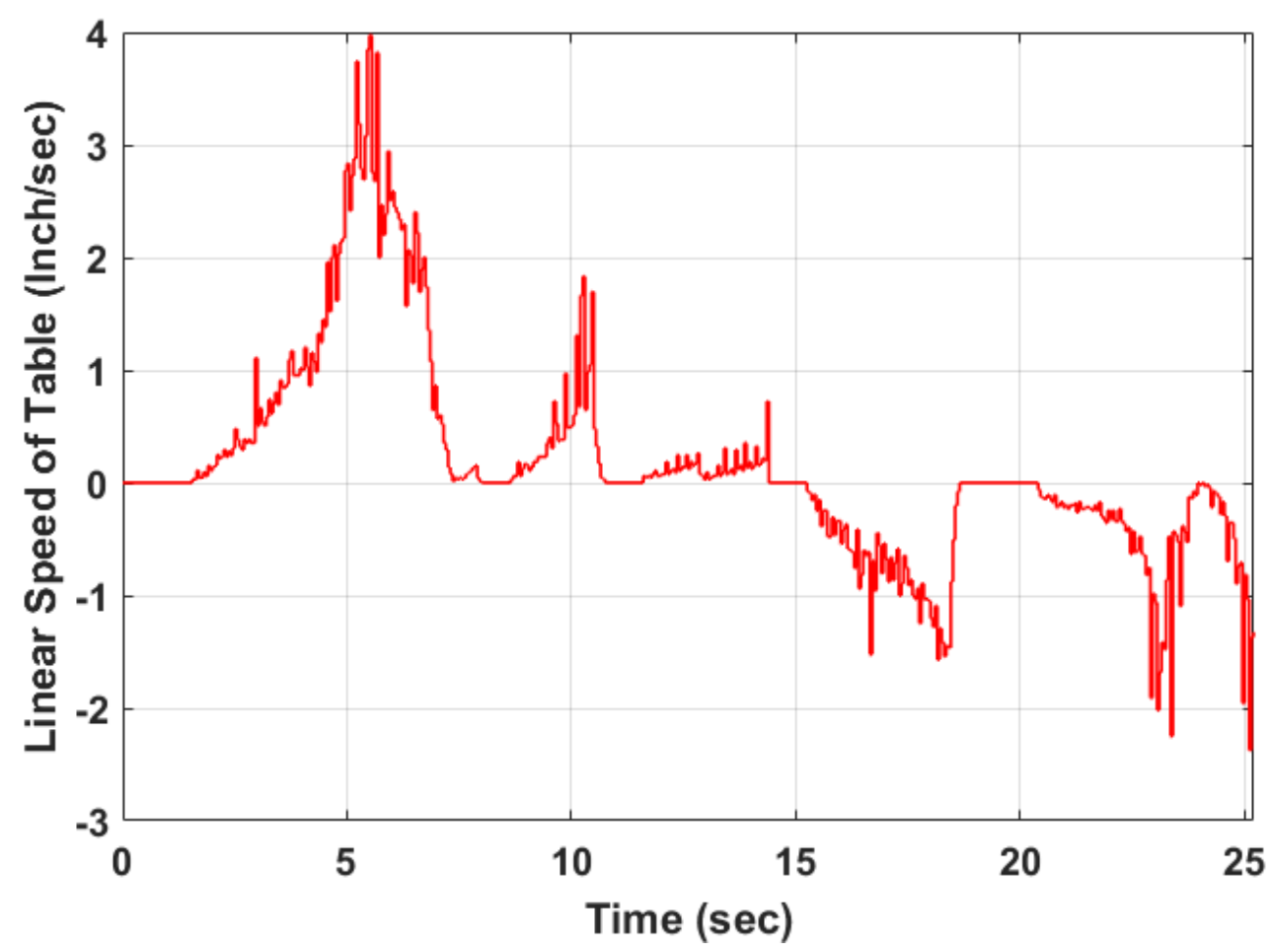

Figure 7. The actual linear speed of servomechanism table. 


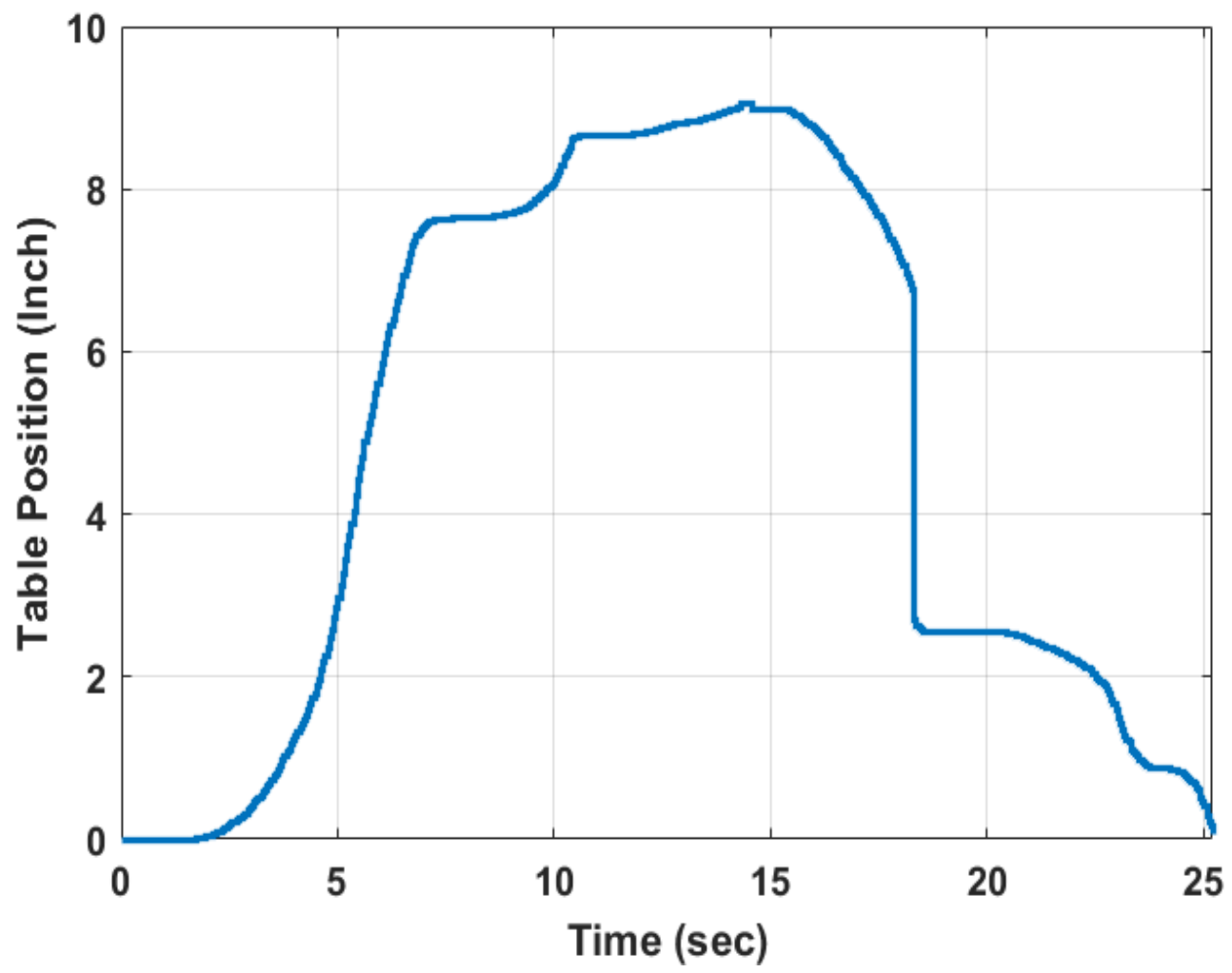

Figure 8. The actual Position of servomechanism table.

The general linear transfer function of such a system may be written as follows Eq. (16).

$$
\frac{y(s)}{u(s)}=\frac{k}{a_{n} \cdot S^{n}+a_{n-1} \cdot S^{n-1}+\cdots+a_{0}}
$$

Where:

$y(s)$ : Linear speed of one stage table.

$u(s)$ : Input signal to DC motor driver.

$\mathrm{n}:$ System order.

$k, a_{n}, \ldots, a_{0}$ : The estimated parameters of the approximate transfer function.

Sometimes, the nonlinear components (friction and backlash) in the system are the obstacle to reach accurate identified model Even if we increase the degree of the order system. So, we resort to nonlinear ARX model to improve the accuracy of the identified model.

Figure 9 demonstrates the linear speed of one stage table servomechanism for actual experimental setup, second order identified model and nonlinear ARX identified model. It is obvious that the nonlinear ARX identified can simulate the behavior of actual experimental setup compared with the second order identified model. 


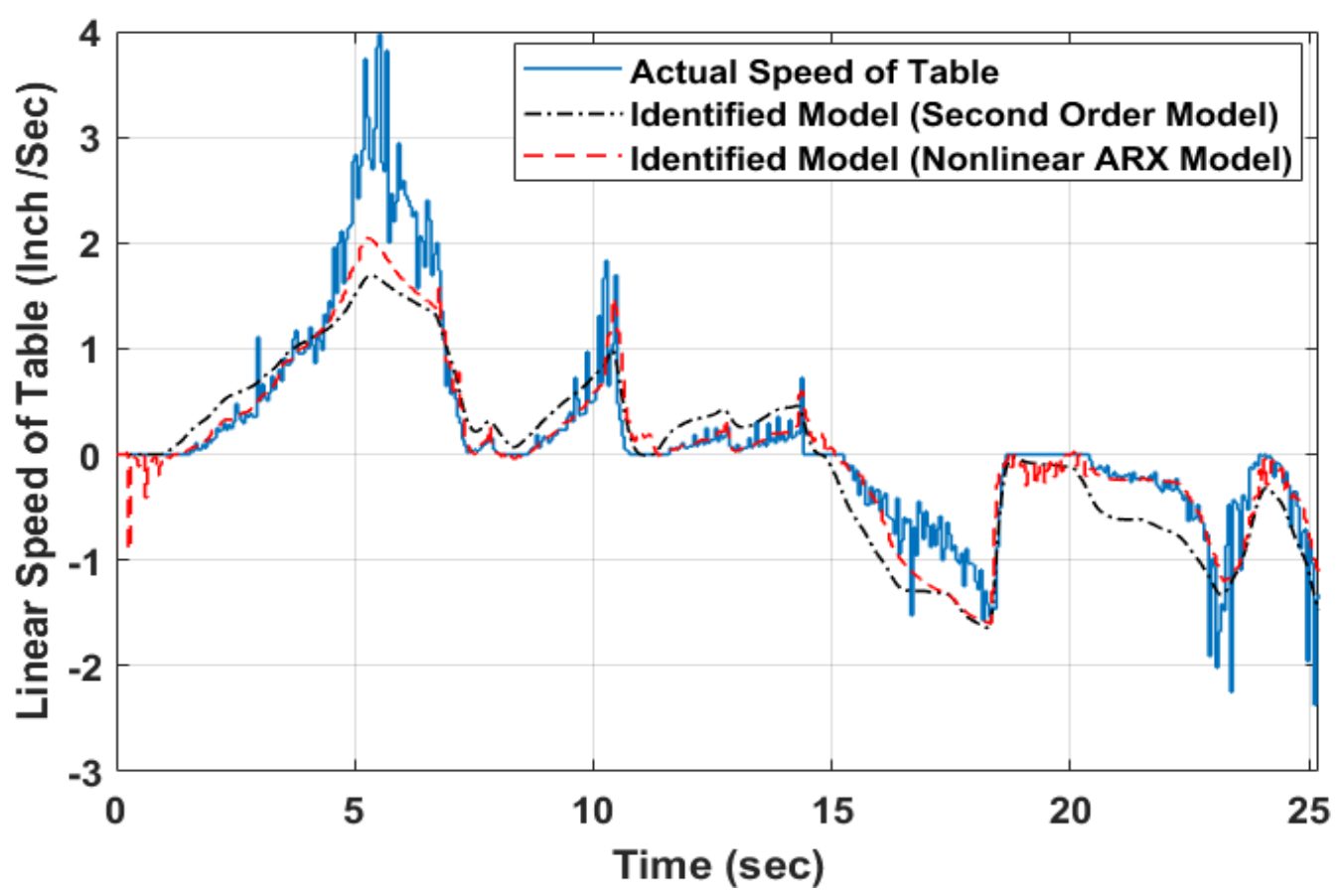

Figure 9. The linear speed of one stage table servomechanism for actual experimental setup and identified models.

Table 2 demonstrates the mean square error of each identified model. It can be noted that the nonlinear ARX identified model has the minimum mean square with respect to the second order identified model.

Finally, it can be summarized that the nonlinear ARX identified model can represent the one stage table servomechanism significantly. So, this model will be used to help us to can design and implement the enhanced nonlinear PID controller.

Table 2. Mean square error of each identified model.

\begin{tabular}{clc}
\hline No. & System Identification Method & $\begin{array}{c}\text { Mean Square } \\
\text { Error }\end{array}$ \\
\hline 1 & Identified Model (second order model) & $\mathbf{0 . 1 9 7 3}$ \\
\hline 2 & Identified Model (nonlinear ARX model) & $\mathbf{0 . 0 5 9 1 2}$ \\
\hline
\end{tabular}

\section{ENHANCED NONLINEAR PID CONTROL}

This section demonstrates the algorithm and the design steps of both the linear PID controller and the enhanced nonlinear PID controller. It is known that the transfer function of the linear PID controller is $K(s)=K_{P}+\frac{K_{i}}{s}+K_{d} s$. Where $K_{p}, K_{i}, k_{d}$ are proportional, integral and differential parameters respectively. The task of each gain of a PID controller can be defined as follows, the proportional gain reduced the error responses of the dynamic system, the integral gain rejects the steady-state error, and lastly, the derivative gain diminishes the dynamic response and enhances the system stability [23]. 
In spite of linear fixed parameters PID controllers are often suitable for controlling a simple physical process, the demands for high performance control with different operating point conditions or environmental parameters are often beyond the abilities of simple PID controllers. It can improve the performance of linear PID controllers using several techniques which will be established to increase the flexibility and robustness for instance, the self-tuning method, general predictive control, neural networks strategy and fuzzy logic, and other methods [24].

Among these techniques, nonlinear PID (NPID) control is presented as one of the most appropriate and effective methods for industrial applications. The nonlinear PID (NPID) control has found in form two broad categories of applications. The first category particular to nonlinear systems, where NPID control is used to absorb the nonlinearity while, the second category deals with linear systems, where NPID control is used to obtain enhanced performance not realizable by a linear PID control, such as reduced overshoot, diminished rise time for step or rapid command input, obtained better tracking accuracy and used to compensate the nonlinearity and disturbances in system [25]. The NPID controllers have the advantage of high initial gain to achieve a fast dynamic response, continued with a low gain to avoid an unstable behavior. In this study, the traditional linear PID controller can be enhanced by combining a sector-bounded nonlinear gain into a linear fixed gain PID control architecture.

The proposed enhanced nonlinear PID (NPID) controller consists of two parts. The first part is a sector bounded nonlinear gain $K_{n}(e)$ while, the second part is a linear fixedgain PID controller $(K \mathrm{p}, K \mathrm{i}$, and $K \mathrm{~d})$. The nonlinear gain $K_{n}(e)$ is a sector-bounded function of the error $\mathrm{e}(\mathrm{t})$. the previous researches have been considered the nonlinear gain $K_{n}(e)$ as a one scalar value.

The new in this paper, The $K_{n}(e)$ acts as a row vector can expressed as $K_{n}(e)=$ $\left[K_{n 1}(e) \quad K_{n 2}(e) \quad K_{n 3}(e)\right]$ which will lead to improve the performance of nonlinear PID controller where the value of nonlinear gain changes according to the error and the type of fixed parameters ( $\mathrm{Kp}, \mathrm{Ki}$, and $\mathrm{Kd})$ as shown in figure 10 .

The proposed form of NPID control can be described as in Eq. (17) and

$$
u(t)=K_{p}\left[K_{n 1}(e) \cdot e(t)\right]+K_{i} \int_{0}^{t}\left[K_{n 2}(e) \cdot e(t)\right] d t+K_{d}\left[K_{n 3}(e) \cdot \frac{d e(t)}{d t}\right]
$$

Where $K_{n 1}(e), K_{n 2}(e)$ and $K_{n 3}(e)$ are nonlinear gains. The nonlinear gains represent any general nonlinear function of the error e which is bounded in the sector $0<K_{n}(e)<$ $K_{n}(e) \max$.

There is a wide range of choices available for the nonlinear gain $K_{n}(e)$. One simple form of the nonlinear gain function can be described as Eq. (18).

Where $i=1,2,3$.

$$
K_{n i}(e)=\operatorname{ch}\left(w_{i} e\right)=\frac{\exp \left(w_{i} e\right)+\exp \left(-w_{i} e\right)}{2}
$$

$$
e=\left\{\begin{array}{ll}
e & |e| \leq e_{\max } \\
e_{\max } \operatorname{sgn}(e) & |e|>e_{\max }
\end{array}\right\}
$$

where $w_{i}$ and $e_{\max }$ are user-defined positive constants. The nonlinear gain $K_{n}(e)$ is lower bounded by $K_{n}(e) \min =1$ when e $=0$, and upper-bounded by $K_{n}(e) \max =\operatorname{ch}\left(w_{i} e_{\max }\right)$. Therefore, $e_{\max }$ stand for the range of deviation, and $w_{i}$ describes the rate of variation of $K_{n}(e)$. 


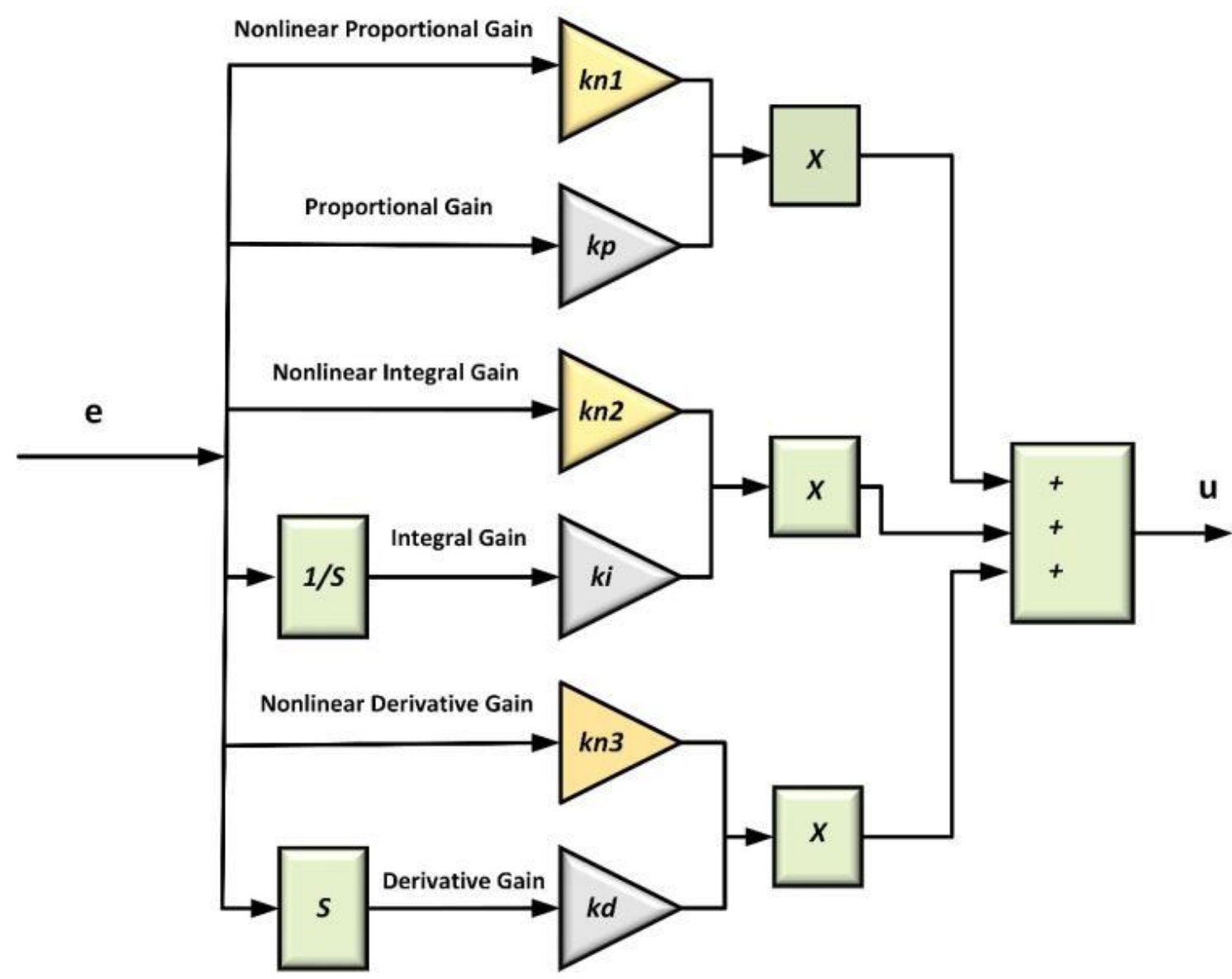

Figure 10. The proposed structure of NPID Control.

The one stage servomechanism system needs to two cascaded controllers, the first controller is the velocity controller while, the second controller is the position controller. Usually in position controller the integral part will be eliminated to be the output of position controller reference speed for velocity controller.

The critical point in the PID and NPID controllers are selecting the proper parameters to be appropriate for the controlled plant. There are different approaches to find the parameters of PID controller for instance, try and error and Ziegler-Nichols method but, most of these approaches are rough roads. In this paper, the harmony search optimization technique will be used to obtain the optimal values of both PID and NPID controller parameters according to the objective function as shown in Eq. (20).

$$
f=\frac{1}{\left(1-e^{-\beta}\right)\left(M_{p}+e_{s s}\right)+e^{-\beta}\left(t_{s}-t_{r}\right)}
$$

Where $M_{p}$ is the overshoot of system response, $e_{s s}$ is the steady state error, $t_{s}$ is the settling time and $t_{r}$ is the rise time. Also, this objective function is able to compromise the designer demand by the weighting parameter value $(\beta)$. The parameter is set larger than 0.7 to reduce over shoot and steady-state error. If this parameter is set smaller than 0.7 the rise time and settling time will be reduced.

Harmony search (HS) was suggested by Zong Woo Geem in 2001. It is well known that HS is a phenomenon-mimicking algorithm inspired by the improvisation process of musicians [15]. The analogy between improvisation and optimization is likely as follows: 
1) Each musician corresponds to each decision variable (controller parameters).

2) Musical instrument's pitch range corresponds to the decision variable's value range.

3) Musical harmony at a certain time corresponds to the solution vector at certain

4) iteration.

5) Audience's aesthetics corresponds to the objective function to be minimized or

6) maximized.

Figure 11 shows the complete harmony search tuning system for the enhanced nonlinear PID controller.

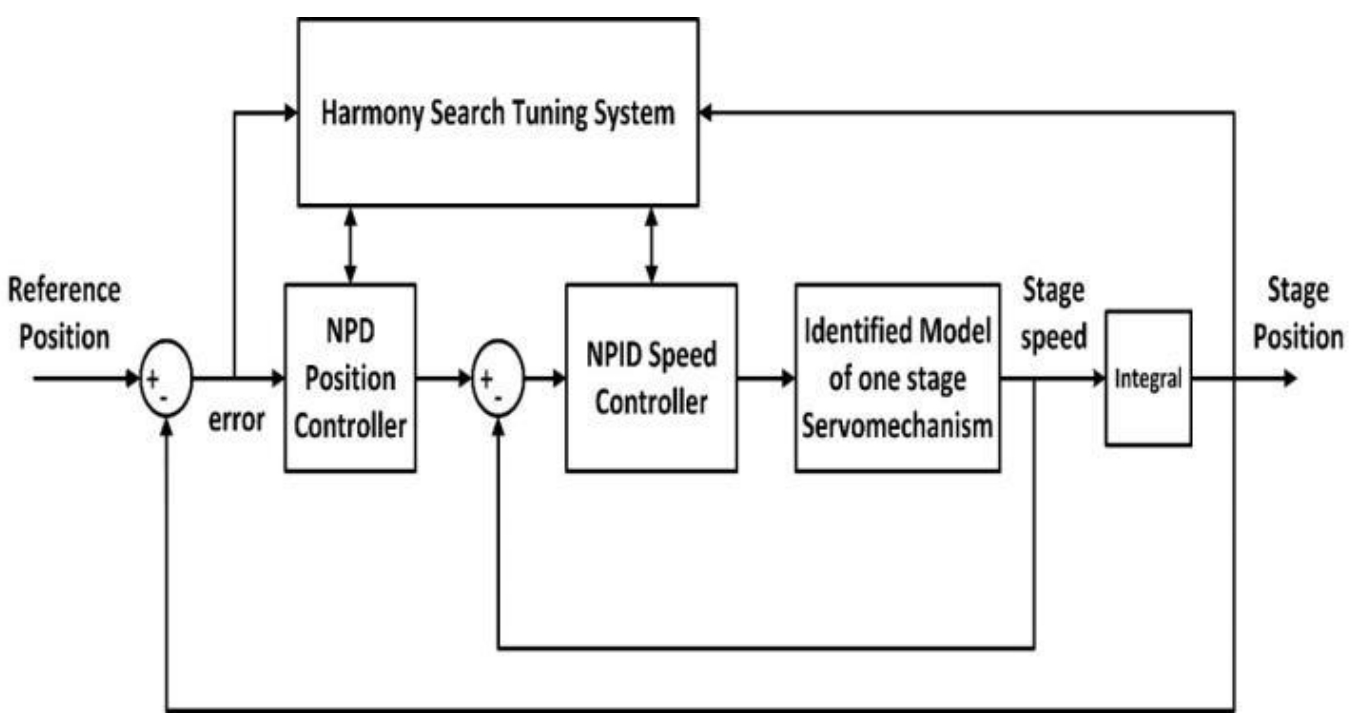

Figure 11. Closed loop system with Harmony search tuning system.

Table 3 demonstrates the obtained parameters values using the harmony search tuning system. The overall closed loop system has two controllers (position and speed controller) in case of the position control the integral part will be eliminated for both the nonlinear PID controller and the PID control.

Table 3. The obtained parameters of each control technique.

\begin{tabular}{|c|c|c|c|c|c|c|c|c|c|c|}
\hline $\begin{array}{l}\text { Controller } \\
\text { Type }\end{array}$ & \multicolumn{4}{|c|}{$\begin{array}{c}\text { Position Controller } \\
\text { (without Integral part) }\end{array}$} & \multicolumn{6}{|c|}{ Speed Controller } \\
\hline \multirow{2}{*}{$\begin{array}{c}\text { NPID } \\
\text { Controller }\end{array}$} & $K_{p}$ & $w_{1}$ & $K_{d}$ & $w_{3}$ & $K_{p}$ & $w_{1}$ & $K_{i}$ & $w_{2}$ & $K_{d}$ & $w_{3}$ \\
\hline & 10.45 & 0.67 & 0.0045 & 0.93 & $\begin{array}{l}50 . \\
56\end{array}$ & 0.96 & 0.0067 & 0.034 & 5.054 & 0.0456 \\
\hline $\begin{array}{c}\text { PID } \\
\text { Controller }\end{array}$ & \multicolumn{2}{|c|}{$K_{p}$} & \multicolumn{2}{|c|}{$K_{d}$} & \multicolumn{2}{|c|}{$K_{p}$} & \multicolumn{2}{|c|}{$K_{i}$} & \multicolumn{2}{|c|}{$K_{d}$} \\
\hline
\end{tabular}

\section{EXPERIMENTAL AND SIMULATION RESULTS}

This section investigates the performance of one stage servomechanism system using both the enhanced nonlinear PID controller and the linear PID controller where the obtained parameters using harmony search will be applied in each control technique 
simulation and practical. The required for each control to follow a position reference trajectory in a short time with good accuracy [21], [23].

Figure 12 shows the performance of one stage servomechanism drive system with each control technique at a constant preselected position reference test where the reference of stage position will be adjusted to 7 inches. The proposed controllers will be applied to the identified model (simulation results) and the experiment setup (experimental results). The stage begins moving from the zero position to the position reference. The behavior of stage from zero position to the position reference depends on the type of each control technique. It is noted that the performance of nonlinear PID controller better than the PID controller where the NPID controller can reach the position reference faster than the PID controller (minimum rise time and settling time). Also, the simulation results expected the behavior of each control technique without using the actual experimental setup. Small differences between the simulation and the experimental results because of the noise, system uncertainty, and NI Card time delay. Both simulation results and experimental results are summarized in table 4.

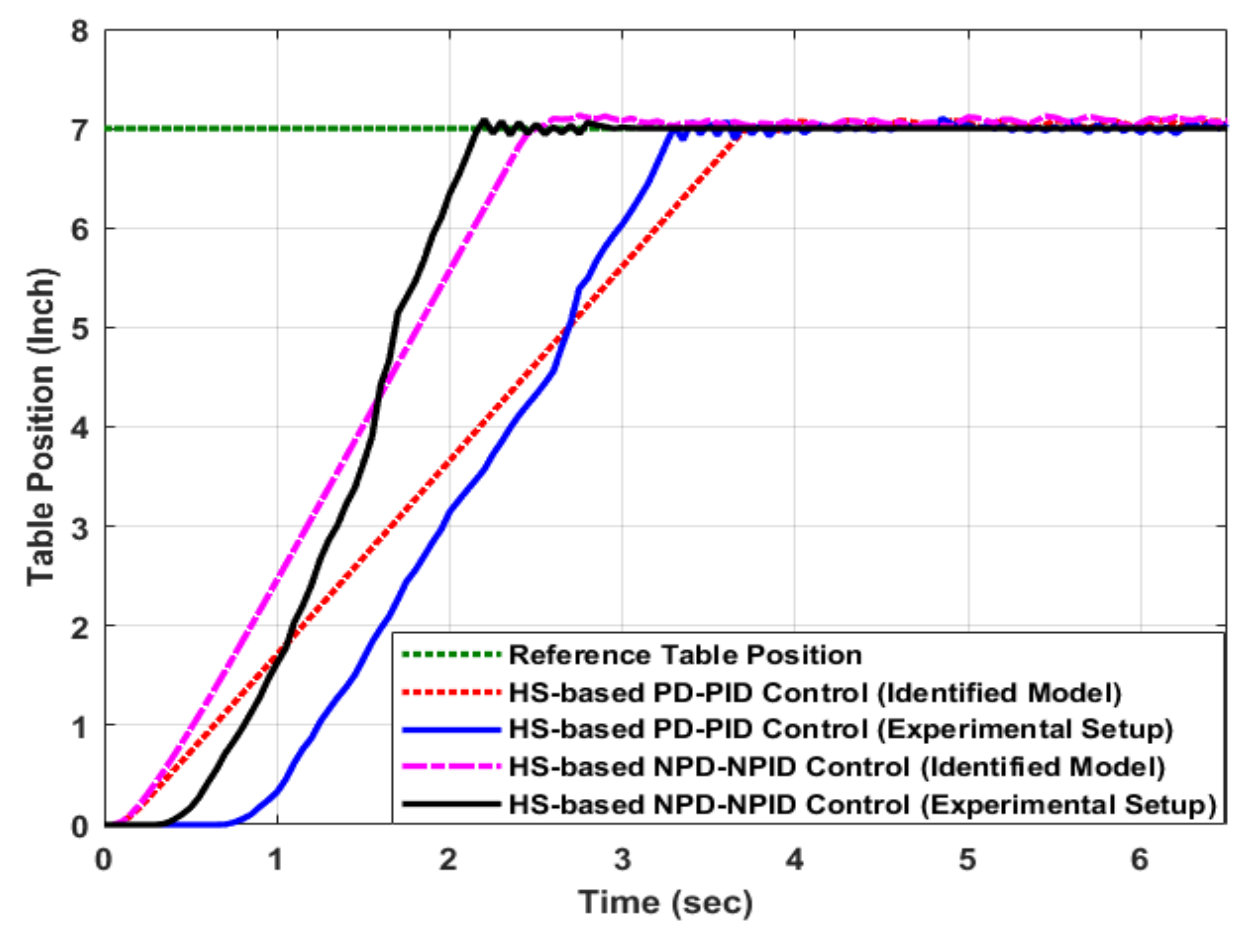

Figure 12. The response of each control technique at a constant reference position applied to the identified model and the experimental setup.

Table 4. Controller techniques performance.

\begin{tabular}{|c|c|c|c|c|}
\hline \multicolumn{2}{|c|}{ CONTROLLER TYPE } & $\begin{array}{l}\text { RISE } \\
\text { TIME }\end{array}$ & $\begin{array}{l}\text { SETTLING } \\
\text { TIME }\end{array}$ & OVERSHOOT \\
\hline \multirow{2}{*}{$\begin{array}{l}\text { LINEAR PD - PID } \\
\text { CONTROLLER }\end{array}$} & Identified Model & 2.6625 & 3.3963 & 1.1772 \\
\hline & $\begin{array}{l}\text { Experimental } \\
\text { Setup }\end{array}$ & 1.9810 & 3.6529 & 0.7861 \\
\hline \multirow{2}{*}{$\begin{array}{l}\text { NONLINEAR PD - PID } \\
\text { CONTROLLER }\end{array}$} & Identified Model & 1.5492 & 2.4466 & 0.6991 \\
\hline & $\begin{array}{l}\text { Experimental } \\
\text { Setup }\end{array}$ & 1.2958 & 2.1295 & 1.2964 \\
\hline
\end{tabular}


Figure 13 shows the speed controller output for each control type at a constant reference position applied to the identified model and the experimental setup. It is clear that the simulation results and practical results are close. Also, there is shuttering at steady state in each control technique due to the noise and the friction.

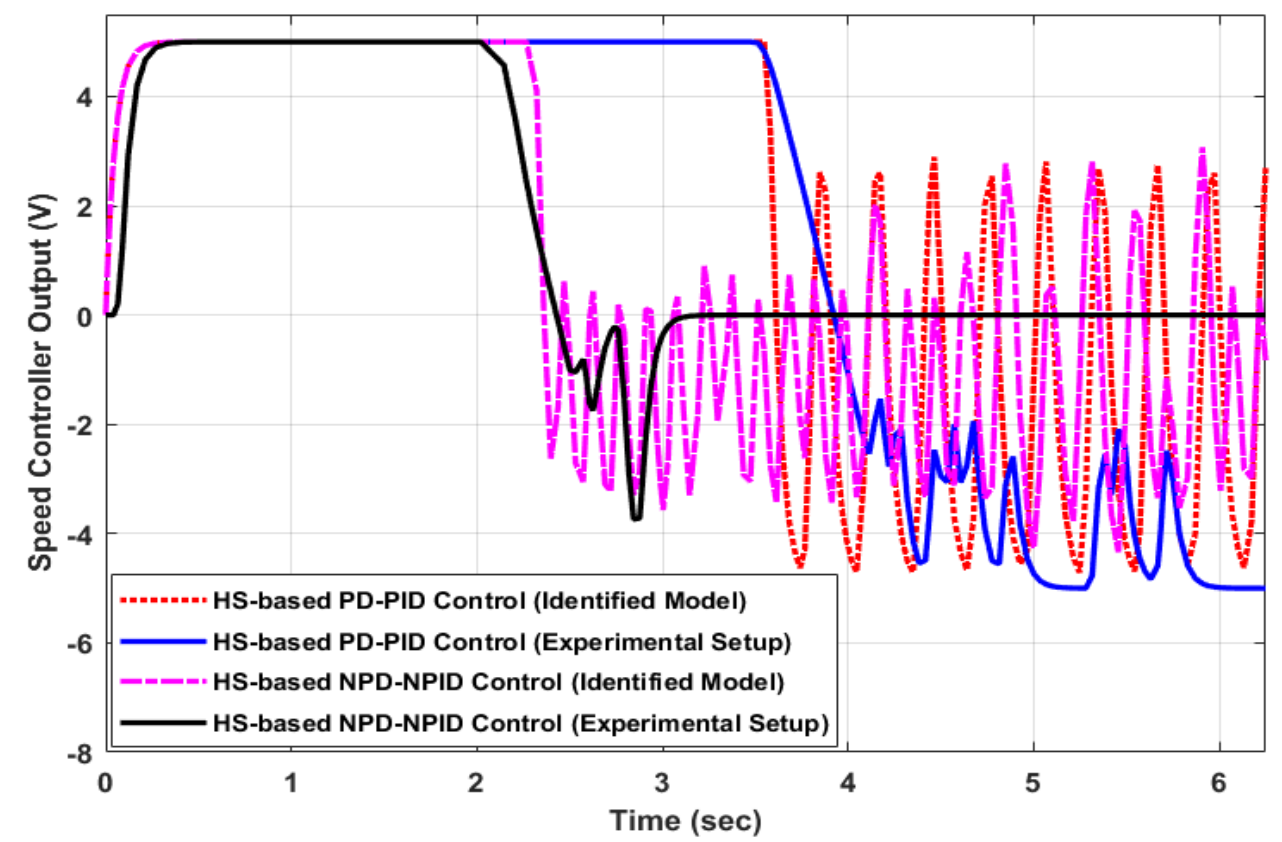

Figure 13. The output of each control technique at a constant reference position applied to the identified model and the experimental setup.

Figure 14 shows the performance of each control technique at different commands of reference position test where the position reference will be changed through this experiment. It can be noted that the nonlinear PID controller can follow the position reference rapidly compared to the PID controller where the proposed NPID control is faster than the PID control with percent $\mathbf{4 0 \%}$ approximately which will lead to save the machining time cycles and increase the productivity. 


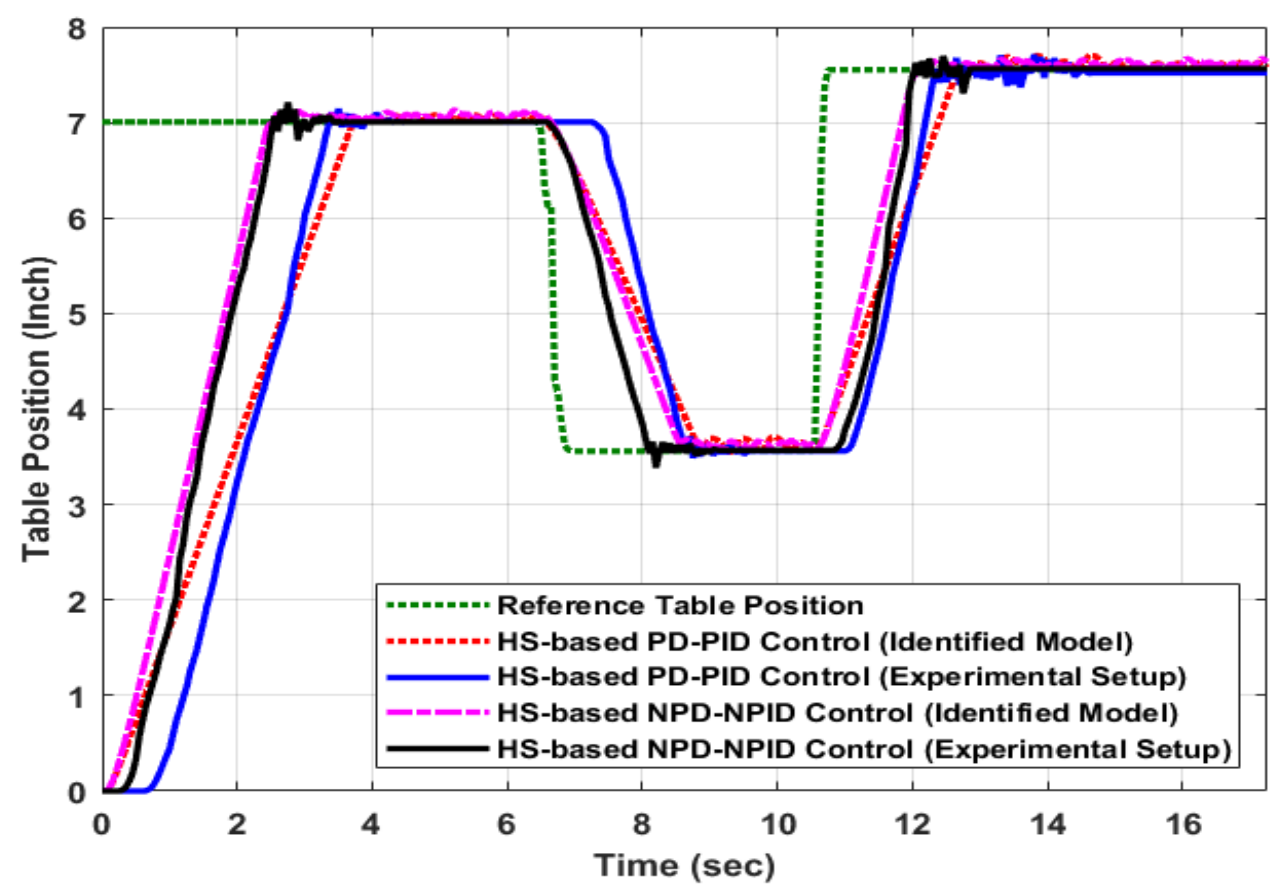

Figure 14. The response of each control technique at different commands of reference position applied to the identified model and the experimental setup.

Figure 15 illustrates the speed controller output for each control type applied to the identified model and the experimental setup at different commands of position reference. It is clear that the simulation results and practical results are identical approximately. Moreover, the shuttering will appear when the stage reaches the required position reference command because of the noise and the friction between the nut and the screw.

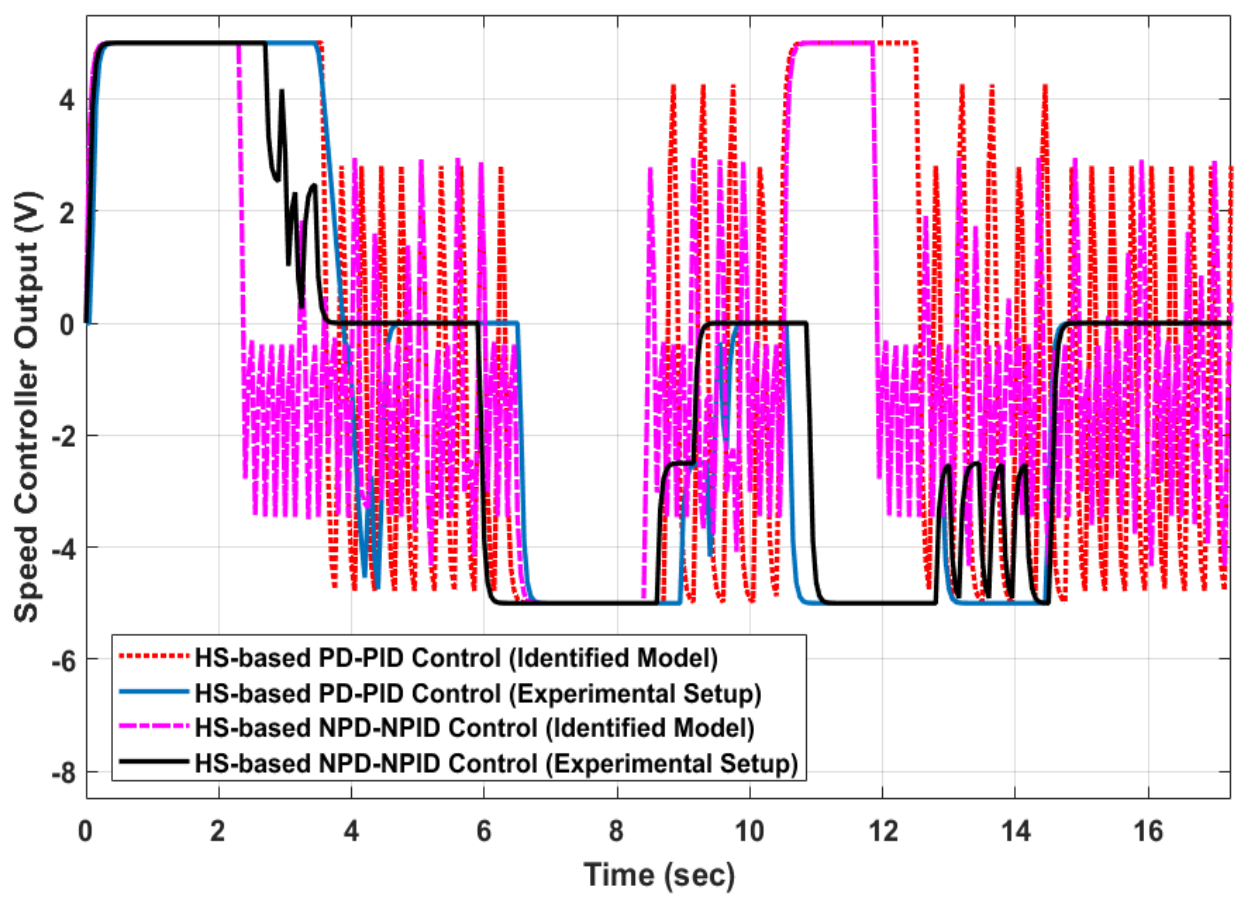

Figure 15. The output of each control technique at different commands of reference position applied to the identified model and the experimental setup. 


\section{CONCLUSION}

A practical implementation for a new form of nonlinear PID (NPID) control was presented to achieve high-performance motion control of one stage servomechanism system. Firstly, an identified model was implemented via collecting the experimental input / output data and entering it to MATLAB system identification toolbox. Secondly, the harmony search optimization was used to obtain the optimum values of controller parameters based on a certain cost function. Lastly, the simulation results would be executed in real time by LABVIEW software. Also, the performance of an enhanced NPID controller compared to the linear PID controller to ensure the robustness. Processing experiments demonstrate that the enhanced nonlinear PID controller is more robust and can accommodate rapidly the position error com the linear PID control. The enhanced NPID control has minimum rise and settling time which will reduce the machining cycles times in industrial processes.

\section{ACKNOWLEDGEMENTS}

The authors would like to be obliged to Future University in Egypt for providing laboratory facilities.

\section{REFERENCES}

[1] E. Yuliza, H. Habil, R. A. Salam, M. M. Munir, M. Abdullah. Development of a Simple Single-Axis Motion Table System for Testing Tilt Sensors. Procedia Eng. 2017;170:378-383.

[2] W. Lee, C. Lee, Y. Hun, B. Min.Friction compensation controller for load varying machine tool feed drive. 2015; 96: 47-54.

[3] P. Perz, I. Malujda, D. Wilczy, P. Tarkowski. Methods of controlling a hybrid positioning system using LabVIEW. Procedia Eng. 2017;177:339-346.

[4] P. Zhao, J. Huang,Y. Shi. Nonlinear dynamics of the milling head drive mechanism in five-axis CNC machine tools. Int. J. Adv. Manuf. Technol. 2017.

[5] C. Abeykoon. Single screw extrusion control: A comprehensive review and directions for improvements. Control Eng. Pract. 2016; 51:69-80.

[6] M. Omar, M. A. Ebrahim, A. M. F. Bendary. Tuning of PID Controller for Load Frequency Control Problem via Harmony Search Algorithm. Indones. J. Electr. Eng. Comput. 2016; 2:255-263.

[7] M. A. Shamseldin, A. A. El-samahy, A. M. A. Ghany. Different Techniques of Self-Tuning FOPID Control for Brushless DC Motor. MEPCON. 2016.

[8] M. A. A. Ghany, M. A. Shamseldin, A. M. A. Ghany. A Novel Fuzzy Self Tuning Technique of Single Neuron PID Controller for Brushless DC Motor. Int. J. Power Electron. Drive Syst. 2017; 8:1705-1713.

[9] F. Wang, C. Liang, Z. Ma, X. Zhao, Y. Tian, D. Zhang. Dynamic analysis of an $\mathrm{XY}$ positioning table. International Conference on Manipulation, Manufacturing and Measurement on the Nanoscale. 2013; 51205279:211-214.

[10] B. Feng, D. Zhang, J. Yang, S. Guo. A Novel Time-Varying Friction Compensation Method for Servomechanism. Hindawi Publ. Corp. Math. Probl. Eng. 2015.

[11] M. R. Stankovi, M. B. Naumović, S. M. Manojlović, S. T. Mitrović. Fuzzy Model 
Reference Adaptive Control of Velocity Servo System. FACTA Univ. Ser. Electron. Energ. 2014; 27: 601-611.

[12] F. L. Li, M. L. Mi, Y. Z. N. Jin. Friction identification and compensation design for precision positioning. Springer. 2017; 120-129.

[13] D. V. L. N. Sastry, M. S. R. Naidu. An Implementation of Different Non Linear PID Controllers on a Single Tank level Control using Matlab. Int. J. Comput. Appl. 2012; 54:6-8.

[14] Y. Ren, Z. Li, F. Zhang. A New Nonlinear PID Controller and its Parameter Design. Int. J. Comput. Electr. Autom. Control Inf. Eng. 2010; 4:1950-1955.

[15] M. A. Ebrahim, F. Bendary. Reduced Size Harmony Search Algorithm for Optimization. Journal of Electrical Engineering. 2016; 1-8.

[16] J. Ye, H. Hu, Z. Wang, R. Sheng. Design of Model Elevator Control System Based on NI CompactRIO and LabVIEW. 9th International Symposium on Computational Intelligence and Design (ISCID). 2016; 68-73.

[17] Y. Naung, A. Schagin, H. L. Oo, K. Z. Ye, Z. M. Khaing. Implementation of data driven control system of DC motor by using system identification process. IEEE Conference of Russian Young Researchers in Electrical and Electronic Engineering (EIConRus), Moscow. 2018; 1801-1804.

[18] Cheng He and Z. Feng. Research on parmeters of acquisition model based on nonlinear least squares method. 2011 International Conference on Remote Sensing, Environment and Transportation Engineering.2011;1499-1502.

[19] P. Zhao, Y. Shi. Robust control of the A-axis with friction variation and parameters uncertainty in five-axis CNC machine tools. J. Mech. Eng. Sci. 2014.

[20] K. R. Asha, P. S. Tasleem, A. V. R. Kumar, S. M. Swamy, K. R. Rekha. Real Time Speed Control of a DC Motor by Temperature Variation Using LabVIEW and Arduino. International Conference on Recent Advances in Electronics and Communication Technology (ICRAECT), Bangalore. 2017; 72-75.

[21] M. Ekici, H. Kahveci, A. S. Akpinar. A LabVIEW based submarine depth control simulator with PID and fuzzy controller. IEEE INISTA, Albena. 2013;1-6.

[22] M. A. Shamseldin, M. A. Eissa, A. A. El-samahy. Practical Implementation of GA-Based PID Controller for Brushless DC Motor. 17th International Middle East Power System Conference (MEPCON'15). 2015.

[23] N. A. Anang, L. Abdullah, Z. Jamaludin, T.H. Chiew, M. Maharof, S.N.S. Salim, Z. Retas, S.C.K. Junoh. Tracking performance of NPID controller for cutting force disturbance of ball screw drive. Journal of Mechanical Engineering and Sciences. 2017;11: 3227-3239.

[24] T.H. Chiew, Z. Jamaludin, A.Y. Bani Hashim, L. Abdullah, N.A. Rafan, M. Maharof. Second order sliding mode control for direct drive positioning system. Journal of Mechanical Engineering and Sciences. 2017;11: 3206-3216.

[25] Ma Quanjin, M.R.M.Rejab, I.M. Sahat, M. Amiruddin, D. Bachtiar, J.P. Siregar, M.I.Ibrahim. Design of Portable 3-axis filament winding machine with inexpensive control system. Journal of Mechanical Engineering and Sciences. 2018; 12: 3479-3493. 